\title{
Traumatic life events and posttraumatic stress disorder among Mexican adolescents: results from a survey
}

\author{
Ricardo Orozco, MSc, ${ }^{(1,2)}$ Guilherme Borges, ScD, ${ }^{(2,3)}$ Corina Benjet, PhD, ${ }^{(2)}$ \\ María Elena Medina-Mora, PhD, ${ }^{(2)}$ Lizbeth López-Carrillo, PhD, ${ }^{(4)}$
}

\section{Orozco R, Borges G, Benjet C, Medina-Mora ME, López-Carrillo L. Traumatic life events and posttraumatic stress disorder among Mexican adolescents: results from a survey. Salud Publica Mex 2008;50 suppl I:S29-S37.}

\begin{abstract}
Objective.To estimate the prevalence and the association of Traumatic Life Events (LEs) and Posttraumatic Stress Disorder (PTSD) among the Mexico City Metropolitan Area (MCMA) adolescent population. Material and Methods.Adolescents aged 12 to 17 were administered the adolescent version of the World Mental Health Composite International Diagnostic Interview $(n=3005)$. Data were collected using a stratified, multistage and probability sample. Prevalence, odds ratios and 95\% confidence intervals for LEs and PTSD (assessed with DSM-IV criteria) were obtained. Results. The percentage of adolescents reporting at least one traumatic event in their lifetimes was $68.9 \%$, with differences by sex. Prevalence for PTSD were $1.8 \%$ (2.4\% females and I.2\% males), and sexualrelated traumas were the LEs most associated with PTSD $[O R=3.9(C 195 \%=I .8-8.2)]$, adjusted by sex, education and age. Conclusions. Exposure to traumatic life events is not uncommon among Mexico City adolescents. Effort should be made to reduce child and adolescent sexual abuse, a very traumatic event highly associated with PTSD.
\end{abstract}

Key words: stress disorders; post-traumatic;adolescent; sexual violence; violence; Mexico
Orozco R, Borges G, Benjet C, Medina-Mora ME, López-Carrillo L.

Eventos traumáticos de vida y trastorno de estrés postraumático en adolescentes mexicanos: resultados de encuesta. Salud Publica Mex 2008;50 supl I:S29-S37.

\section{Resumen}

Objetivo. Estimar la prevalencia y la asociación entre los Eventos Traumáticos (ET) y Trastorno de Estrés Postraumático (TEPT) en la población adolescente del Área Metropolitana de la Ciudad de México (AMCM). Material y métodos. 3005 adolescentes del AMCM entre 12 y 17 años fueron entrevistados empleando la versión para adolescentes de la Entrevista Diagnóstica Internacional de Salud Mental, en una muestra probabilística, estratificada y multietápica. Resultados. $68.9 \%$ de los adolescentes en el AMCM reportaron por lo menos un ET alguna vez en su vida, con diferencias por sexo. La prevalencia de TEPT fue I.8\% (2.4\% mujeres y I.2\% hombres), y el abuso sexual se asoció al desarrollo de TEPT $[O R=3.9(C / 95 \%=1.8-8.2)]$, independientemente del sexo, educación o edad. Conclusiones. La exposición a ET es común en los adolescentes. Se debe poner énfasis en los esfuerzos que buscan reducir el abuso sexual en la infancia y la adolescencia, ya que se asocia fuertemente al TEPT.

Palabras clave: trastornos por estrés postraumático; adolescente; violencia sexual; violencia; México

(I) Ministry of Health. Mexico City, Mexico.

(2) National Institute of Psychiatry Ramón de la Fuente. Mexico City, Mexico.

(3) Metropolitan Autonomous University. Mexico City, Mexico.

(4) National Institute of Public Health. Cuernavaca, Mexico.

Received on: April 26, 2007 - Accepted on: November 15, 2007

Address reprint requests to: Ricardo Orozco Zavala. Secretaría de Salud. Dirección General de Evaluación del Desempeño. Reforma 450, piso 12, col. Juárez, 06600 México DF, México.

E-mail:ric_oz@imp.edu.mx,rorozcoz@salud.gob.mx 
$\mathrm{T}$ raumatic Life Events (LEs) -such as violence, accidents, sexual abuse and others-are highly prevalent among the general adult Mexican population, with $68 \%$ of the population having ever been exposed to at least one lifetime LE. ${ }^{1}$ A similar prevalence has been found in studies in the US. ${ }^{2}$ Some LEs, like the unexpected death of a loved one, are equally distributed over the lifespan, while others, like sexual assaults or being beaten up by caregivers, are more likely to occur during childhood or adolescence. In Mexico City, older adolescents reported the greatest number of lifetime stressful life events. ${ }^{3}$ Accidents and violence (mainly outside the home) are the most important -and preventable- LEs in adolescence from a public health point of view, since they are the main cause of health care use for this population. ${ }^{4,5}$

LEs have been identified as a risk factor for mental disorders, the majority of which first manifest during childhood, adolescence and early adulthood. ${ }^{6}$ Many studies have found an association between LEs and addiction, drug use and abuse, ${ }^{7,8}$ depression, ${ }^{9}$ and suicidal behavior. ${ }^{10}$ Several studies have documented the association between childhood sexual abuse and subsequent onset of suicidal behavior as well as with 14 mood, anxiety, and substance use disorders among females and five among males. ${ }^{10-12}$ Violence is the most studied LE and is consistently associated with mental disorders. ${ }^{13-15}$

Of the mental disorders, Posttraumatic Stress Disorder (PTSD) is of particular interest, since it is causally linked (and, therefore, is a direct consequence) of a traumatic event. PTSD is an anxiety disorder that leads to financial burden upon society and individual disability such as greater academic failure and more interpersonal problems. ${ }^{2,16,17}$

To our knowledge, PTSD prevalence has been scarcely documented in the national epidemiologic literature, with a lifetime prevalence of $1.5 \%$ and $2.6 \%$ according to DSM-IV and ICD-10 criteria for PTSD, respectively, among the general adult population. ${ }^{1,18}$ Another study found that $11.5 \%$ of the general population that reported at least one LE met criteria for violence-related PTSD. ${ }^{19}$ However, neither adolescent PTSD prevalence nor the prevalence of a comprehensive list of LEs has been reported yet among adolescents in Mexico City. The goal of this paper is to report the prevalence of LE and its impact on PTSD among a representative sample of Mexico City Metropolitan Area (MCMA) adolescents. This would be the first representative study to achieve this goal in the MCMA adolescent population.

\section{Material and Methods}

This study performs a secondary data analysis from the Mexican Adolescent Mental Health Survey (MAMHS), a multistage, probabilistic and stratified household survey. This survey is part of the World Health Organization's (WHO) World Mental Health Surveys Initiative, and uses a computer-assisted version of the Composite International Diagnostic Interview (CIDI) ${ }^{20}$ in order to assess mental disorders according to the definition and criteria of the Diagnostic and Statistical Manual of Mental Disorders (DSM-IV). ${ }^{21}$ Translation to Spanish was made according to $\mathrm{WHO}$ recommendations.

Written informed consent was obtained from both the adolescent and one parent (or legal guardian), after the interviewer explained the procedures and goals of the study. All participants were given a mental health resources card with the contact information for different institutions, in case they wanted to seek mental health services. The Human Subjects Committee of the National Institute of Psychiatry approved the recruitment, consent and field procedures. ${ }^{22}$

\section{Study population}

Adolescents aged 12 to 17 who were permanent, noninstitutionalized (not living in government institutions) residents in the Mexico City Metropolitan Area (MCMA) were interviewed face-to-face in their homes by trained, non-clinician interviewers, from March through August, 2005. A total of 3005 subjects completed the interview, with a response rate of $71 \%$. Mean interview length was 2.5 hours. For each Strata, PSUs were census count areas (AGEBs or groups of them), as defined by the Instituto Nacional de Estadística, Geografía e Informática (INEGI) in 2000. Secondary sampling units were city blocks (or groups) selected with probability proportional to size. All households within these city block units with adolescents aged 12 to 17 were selected. One eligible member was randomly selected from each of these households with the Kish method of random numbers. More details on the methodology has been published elsewere. ${ }^{23,24}$

\section{Assessment of LE}

The CIDI's PTSD section accounts for 23 different lifetime traumatic events (such as rape, violence, serious injuries, domestic violence, serious sickness, etc.), with questions like: "Were you ever involved in a very serious or life-threatening car accident?" For each LE, age of onset and number of times (or duration) was also asked. Symptoms related to the event and symptoms' duration was asked of the single LE if the participant reported solely one, or the "most upsetting" event if the participant reported more than one LE. After the presentation of this list of events, the respondent was still able to select an "Other/Private Event" category. The "Other/Private Event" category was composed mainly with "Private Event" responses, which allowed the participant to discuss the symptoms 
related to the event without disclosing any details about the specific trauma. Few "Other event" responses were traumas that did not fit in any of the former 21 categories. Due to sample size and similarity between some traumas, a grouping of traumatic events was made for some of the analyses. For a comprehensive list of LEs and their definitions please refer to the appendix.

\section{Assessment of PTSD}

Lifetime PTSD was assessed with all six DSM-IV criteria: ${ }^{21}$ a)the person's response to a traumatic event involved intense fear, helplessness or horror; $b$ )the traumatic event is persistently re-experienced; c)avoidance of stimuli; d)increased arousal; e)symptom duration of at least one month, and f)clinically significant distress or impairment. When people were exposed to more than a single LE, PTSD was assessed only for what the respondent considered the "most upsetting" event. ${ }^{25}$ The validity and reliability of the CIDI's PTSD module is documented elsewhere (kappa $=0.75^{25}$ and kappa $=0.62,{ }^{26}$ respectively).

\section{Data analysis}

Data were weighted to adjust for different probabilities of selection and non-response, based on household size. Post-stratification to the total MCMA adolescent population according to the 2000 census in the target age and sex range was also performed.

In order to take into account the survey's complex design, SUDAAN's CROSSTABS and RLOGIST procedures ${ }^{27}$ were used in order to estimate standard errors (SE) and 95\% confidence intervals (CI) for proportions and odds ratios (OR), respectively, as well as independence Wald's chi-square tests. Gender and total prevalence were calculated for each LE (or grouped LEs). Wald's Chi-square test was conducted to determine female/male differences. Geographic prevalence for Mexico City and the State of Mexico were also performed, Mexico City was divided, according to the Mexican National Institute of Statistics, Geography and Informatics, into three "state coordinations". ${ }^{28}$

Survival curves were estimated using SAS software's LIFETEST procedure, ${ }^{*}$ in order to calculate conditional survival probabilities in one-year periods.

The prevalence of PTSD for each LE was computed and the association between LEs and PTSD was estimated by unconditional logistic regression; two sets

\footnotetext{
* SAS for Windows [computer program]. Version 9.1.3. SAS Institute Inc. Cary, NC, USA: 2003.
}

of analyses were performed, the first model (model 1) included each group of LE adjusted by age, gender and education; the second model (model 2), consisted of best fitted models including those variables that changed the crude estimator in more than $10 \%$. Respondents with at least one lifetime LE were included in all logistic regressions, since they are the only ones at risk for developing PTSD ( $n=2$ 022), and design effects were taken into account for these logistic regressions.

\section{Results}

Table I shows the socio-demographic characteristics of the sample. Frequencies are unweighted, while percent-

Table I

SOCIODEMOGRAPHIC CHARACTERISTICS. Mexico City Metropolitan Area, 2005 (n=3 005)

\begin{tabular}{|c|c|c|}
\hline & $n$ & \%* \\
\hline \multicolumn{3}{|l|}{ Gender } \\
\hline Male & 1440 & 49.9 \\
\hline Female & 1565 & 50.1 \\
\hline \multicolumn{3}{|l|}{ Age } \\
\hline $12-14$ & 1764 & 49.3 \\
\hline $15-17$ & $|24|$ & 50.7 \\
\hline
\end{tabular}

\begin{tabular}{lrc}
$\begin{array}{l}\text { Attending school } \\
\text { Yes }\end{array}$ & 2526 & 81.2 \\
\hline No & 479 & 18.8 \\
$\begin{array}{l}\text { Marital status } \\
\text { Married/ divorced }\end{array}$ & 33 & 1.3 \\
\hline$\quad$ Single & 2972 & 98.7 \\
$\begin{array}{l}\text { Ever had a child } \\
\text { Yes }\end{array}$ & 43 & \\
\hline No & 2962 & 1.7 \\
\hline
\end{tabular}

Ever worked

\begin{tabular}{|c|c|c|}
\hline Yes & 255 & 9.6 \\
\hline No & 2750 & 90.4 \\
\hline \multicolumn{3}{|l|}{ Residence } \\
\hline Mexico City & 1500 & 49.9 \\
\hline State of Mexico & 1505 & 50.1 \\
\hline \multicolumn{3}{|l|}{ Parental education ${ }^{\ddagger}$} \\
\hline None/elementary & 773 & 26.5 \\
\hline Junior high & 1073 & 36.8 \\
\hline High school & 696 & 23.1 \\
\hline Undergraduate/postgraduate & 399 & 13.5 \\
\hline \multicolumn{3}{|l|}{ Parental employment ${ }^{\S}$} \\
\hline Always & 2583 & 85.8 \\
\hline Almost always & 279 & 9.6 \\
\hline Sometimes/ almost never/ never & 136 & 4.5 \\
\hline Without parents/ don't know/ refusal & 5 & 0.1 \\
\hline \multicolumn{3}{|l|}{ * Weighted by sampling factors } \\
\hline \multicolumn{3}{|l|}{ ¥ Maximum education for either parent } \\
\hline$\S$ Parental employment during the adoles & & \\
\hline
\end{tabular}


ages are weighted. About $19 \%$ of adolescents were not attending school at the time of the interview, $1.3 \%$ were married or divorced, $1.7 \%$ had had a child, and about ten percent ever worked.

Traumatic life events were highly prevalent, as shown in table II, with $68.9 \%$ of adolescents having reported at least one lifetime LE. The most common LEs were: unexpected sudden death of a relative $(25.8 \%)$, witnessing domestic violence and being involved in a serious accident $(19.4 \%$ each). There were several gender differences, with males more likely to report accidents, illness, and witnessing or suffering violence outside the home, while females were more likely to report sexual related trauma, witnessing of domestic violence, unexpected death of a loved one as well as Other/Private events. Multiple traumas were also frequent, with $28.2 \%$ of the population reporting two or three events, and $13 \%$ reporting four or more, with no differences in the number of lifetime LEs reported for females and males.

Few significant differences were found across MCMA territories (data not shown but available)."Lifethreatening illness" and being "mugged or threatened with a weapon" were less likely to be reported in the

Table II

Prevalence of traumatic life eVents and posttraumatic stress disorder (eVer in lifetime) by gender, in the Mexico City Metropolitan Area, 2005

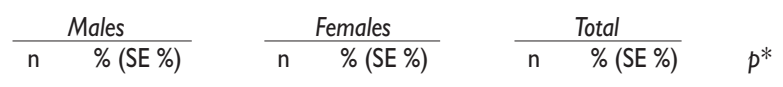

Type of trauma

\begin{tabular}{|c|c|c|c|c|c|c|c|}
\hline I Raped & 9 & $0.6(0.27)$ & 32 & $2.0(0.35)$ & 41 & $1.3(0.23)$ & 0.003 \\
\hline 2 Sexually assaulted & 23 & $1.7(0.27)$ & 108 & $7.7(0.58)$ & 131 & $4.7(0.34)$ & $<0.001$ \\
\hline 3 Beaten up as a child by caregiver & 167 & $12.2(1.06)$ & 216 & $14.2(0.98)$ & 383 & $13.2(0.62)$ & 0.222 \\
\hline 4 In region of terror & 14 & I.I (0.34) & 6 & $0.4(0.15)$ & 20 & $0.7(0.16)$ & 0.107 \\
\hline 5 Kidnapped & 9 & $0.6(0.13)$ & 2 & $0.1(0.09)$ & II & $0.4(0.06)$ & 0.014 \\
\hline 6 Toxic exposure/automobile/life threatening accident & 327 & $23.6(1.43)$ & 239 & $15.3(0.84)$ & 566 & $19.4(0.75)$ & $<0.001$ \\
\hline 7 Disaster & 48 & $3.6(0.68)$ & 41 & $2.6(0.36)$ & 89 & $3.1(0.47)$ & 0.078 \\
\hline 8 Life threatening illness & 112 & $8.1(0.79)$ & 87 & $5.7(0.74)$ & 199 & $6.9(0.47)$ & 0.049 \\
\hline 9 Beaten up by spouse, romantic partner or someone else & 105 & $7.8(0.97)$ & 75 & $5.0(0.49)$ & 180 & $6.4(0.56)$ & 0.012 \\
\hline 0 Mugged or threatened with a weapon & 297 & $22.9(1.00)$ & 139 & $9.5(0.89)$ & 436 & $16.2(0.53)$ & $<0.001$ \\
\hline I Stalked & 64 & $5.1(0.66)$ & 144 & $9.1(0.92)$ & 208 & $7.1(0.61)$ & 0.001 \\
\hline 2 Unexpected death of a loved one & 322 & $22.9(1.05)$ & 437 & $28.7(1.29)$ & 759 & $25.8(0.92)$ & $<0.001$ \\
\hline 3 Traumatic event of a loved one & 88 & $6.8(0.8 I)$ & 132 & $8.6(0.80)$ & 220 & $7.7(0.59)$ & 0.104 \\
\hline 4 Witnessed physical fights at home & 234 & $17.2(1.36)$ & 342 & $21.6(0.99)$ & 576 & $19.4(0.85)$ & 0.013 \\
\hline 5 Witnessed death or dead body or saw someone else seriously hurt & 271 & $19.7(0.97)$ & 222 & $15.0(0.94)$ & 493 & $17.3(0.72)$ & 0.001 \\
\hline 6 Accidentally caused serious injury or death & 37 & $3.0(0.40)$ & 15 & $1.0(0.34)$ & 52 & $2.0(0.22)$ & 0.002 \\
\hline 7 Purposely injured, tortured or killed someone & 12 & $0.8(0.21)$ & 9 & $0.6(0.21)$ & 21 & $0.7(0.16)$ & 0.309 \\
\hline 8 Other/private event & 69 & $5.0(0.74)$ & 124 & $8.2(0.82)$ & 193 & $6.6(0.59)$ & 0.004 \\
\hline
\end{tabular}

Frequency of trauma

\begin{tabular}{|c|c|c|c|c|c|c|c|}
\hline None & 485 & $31.3(0.96)$ & 498 & $30.9(1.10)$ & 983 & $31 . I(0.77)$ & 0.179 \\
\hline Only one & 378 & $25.8(1.19)$ & 468 & $29.6(1.11)$ & 846 & $27.7(0.77)$ & \\
\hline Two or three & 398 & $29.4(1.47)$ & 414 & $27.1(1.40)$ & 812 & $28.2(1.02)$ & \\
\hline Four or more & 179 & $13.6(0.96)$ & 185 & $12.4(0.95)$ & 364 & $13.0(0.68)$ & \\
\hline Any trauma & 955 & $68.7(0.96)$ & 1067 & $69.1(1.10)$ & 2022 & $68.9(0.77)$ & 0.747 \\
\hline Posttraumatic stress disorder & 15 & $1.2(0.39)$ & 33 & $2.4(0.50)$ & 48 & $1.8(0.36)$ & 0.031 \\
\hline
\end{tabular}


southwest side of Mexico City, and "witnessed death or dead body or saw someone else seriously hurt" were more likely to be reported in the State of Mexico, as well as reports for any trauma.

Survival curves for age of onset of grouped LEs are shown in figure 1. Some LEs appear repeatedly over time, such as accidents, illnesses, death or traumatic event to a loved one, as well as domestic violence (against child or spouses). Some other LEs dramatically appear in early adolescence, such as being a witness or being involved in violence (as a victim or perpetrator).

Interestingly, the "sexual abuse" age of onset and the "Other/Private event" follow a similar survival curve.

Prevalence for PTSD in the MCMA was 1.8\% ( $\mathrm{SE}=0.36)$, and was two times more prevalent in females $(2.4 \%[0.50])$ than in males $(1.2 \%[0.39])$. As shown in table IV, adolescents reporting (a lifetime) sexual abuse (rape or sexual assault) presented the highest PTSD prevalence $(9.7 \%)$ and an odds ratio of $3.9(C I=1.81-8.23)$. "Other/Private event" was also highly associated with PTSD, with an OR=3.3 (1.94-5.73). As evident from this table, increased prevalence of PTSD was found among those who suffered multiple LEs. ORs were also calculated among the subsample of those reporting at least one event. Compared to those with only one event, those with 2 to 3 events and those with 4 or more events had 3.3 (1.63-6.48) and 6.1 (3.08-12.14) increased odds of PTSD, respectively $(p<0.01$ trend test).

Given the large amount of multiple events in this sample, we performed a test of whether sexual abuse and "Other/Private event" were associated with PTSD independently of any other event. When controlling for other LEs that changed the OR by $10 \%$ (model 2) and adding these LEs to the model, none of the other LEs reached statistical significance except for sexual abuse (OR=3.5, $C I=1.54-7.80)$ and "Other/Private event" $(\mathrm{OR}=3.0, \mathrm{CI}=1.73-5.14)$.

\section{Discussion}

Exposure to traumatic life events is not uncommon among Mexico City adolescents, with $69 \%$ having experienced at least one LE and as many as $13 \%$ having experienced four or more LEs. The most common LE was the unexpected death of a loved one, followed by

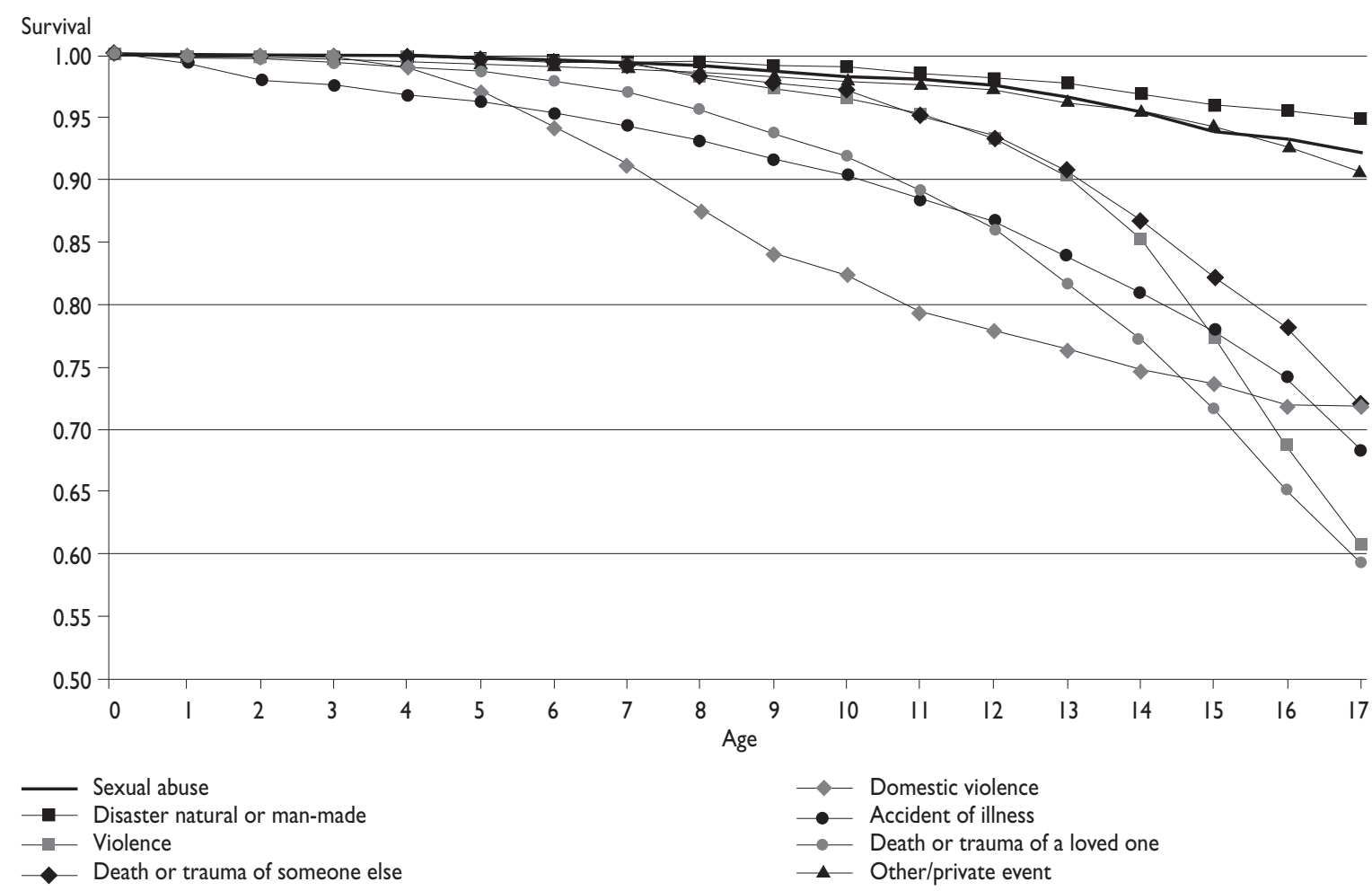

Figure I. Cumulative age-of-onset distribution of lifetime traumatic events. Mexico City Metropolitan Area, 2005 
Table III

RISK OF POSTTRAUMATIC STRESS DISORDER BY GROUP OF TRAUMATIC LIFE EVENTS. Mexico City Metropolitan Area, 2005*

\begin{tabular}{ll}
\multicolumn{2}{c}{ PTSD } \\
\hline Yes (\%)
\end{tabular}

\begin{tabular}{ll}
\multicolumn{2}{c}{ Model $I^{\ddagger}$} \\
\hline OR
\end{tabular}

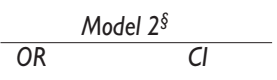

\begin{tabular}{lcccccc}
$\begin{array}{l}\text { Type of trauma } \\
\text { Sexual abuse }\end{array}$ & $13(9.7)$ & 150 & 3.9 & $(1.81-8.23)$ & $3.5^{\#}$ & $(1.54-7.80)$ \\
\hline Domestic violence & $21(3.5)$ & 754 & 1.4 & $(0.66-3.13)$ & $1.1^{\&}$ & $(0.51-2.50)$ \\
\hline Disaster, natural or man-made & $4(4.5)$ & 104 & 2.2 & $(0.52-9.1 \mathrm{I})$ & 2.2 & $(0.52-9.1 \mathrm{I})$ \\
\hline Accident or illness & $22(3.2)$ & 674 & 1.5 & $(0.63-3.69)$ & 1.5 & $(0.63-3.69)$ \\
\hline Violence & $24(3.4)$ & 668 & 1.5 & $(0.76-2.95)$ & 1.5 & $(0.76-2.95)$ \\
\hline Death or trauma of a loved one & $27(3.4)$ & 872 & 1.6 & $(0.67-3.76)$ & 1.6 & $(0.67-3.76)$ \\
\hline Death or trauma of someone else & $14(3.0)$ & 518 & 1.2 & $(0.56-2.36)$ & 1.2 & $(0.56-2.36)$ \\
\hline Other/ Private event & $14(7.7)$ & 179 & 3.3 & $(1.94-5.73)$ & $3.0^{\neq}$ & $(1.73-5.14)$
\end{tabular}

Number of events

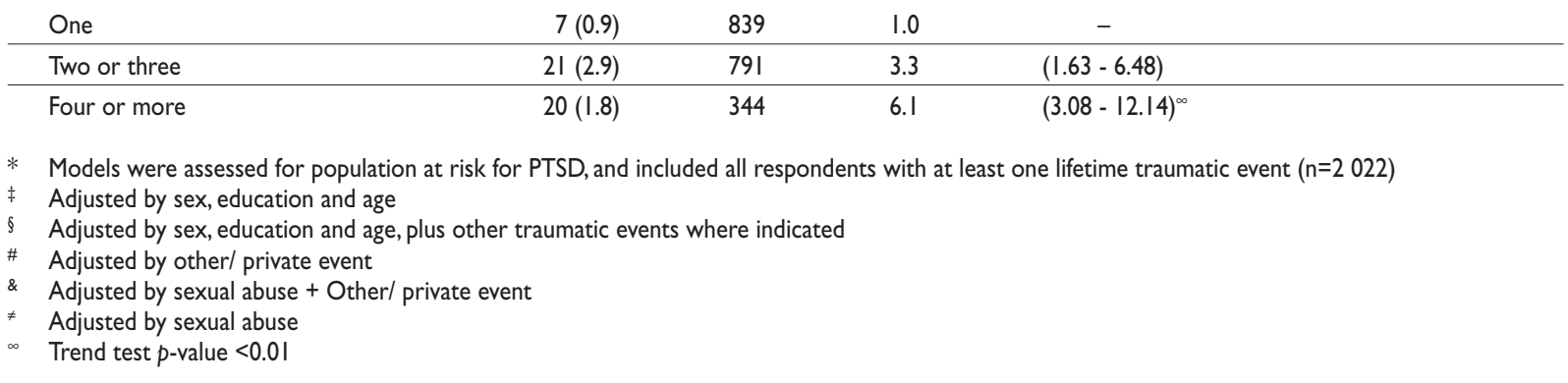

witnessing domestic violence and being involved in a serious accident. The lifetime prevalence of LEs in this sample of MCMA adolescents is strikingly consistent with the national adult estimate. However, given that adolescents have lived shorter lives, one might expect a lower prevalence of LEs. Three possible reasons might account for this similar instead of lower estimate. First, the prevalence of LEs is likely to be higher in a large metropolitan area than for the overall national population; second, adults might fail to report or remember all of their early traumatic life events and third, this cohort of adolescents may be more exposed to LEs than earlier generations. Additionally the similar prevalence between adults and adolescents may not be that surprising given that many LEs such as physical abuse by caregivers and sexual abuse are concentrated in the childhood and adolescent years.

In this study, it was found that the gender distribution of LEs is consistent with findings from previous research with adults in Mexico ${ }^{1}$ and internationally. ${ }^{29,30}$ For example, females are more likely to report sexual abuse, and males more diverse forms of violence, espe- cially outside the home. Traditional gender roles may help explain these differences such that males spend more time outside the home and in more risk-taking activities, whereas females spend more time inside the home and are more vulnerable to sexual aggression.

While the majority of adolescents have suffered a LE, fortunately most do not further develop PTSD. The percentage of the Mexico City adolescents who reported PTSD was $1.8 \%$, similar to the prevalence estimate for Mexican adults and less than half the prevalence estimate for U.S. adolescents $(6.3 \%$ and $3.7 \%$ for US adolescent females and males, respectively). ${ }^{13} \mathrm{~A}$ key question in PTSD research is to determine what factors contribute to whether or not a person exposed to a LE develops PTSD. We examined two such factors: type of LE and number of LEs.

Consistent with the international literature, rape and sexual assault is the traumatic event most likely to result in PTSD. ${ }^{25}$ Moreover, this association may be even stronger, since the "Other/Private event" category seems to be highly related to the former, as can be appreciated in figure 1, where both survival curves are practically the 
same, as are the adjusted ORs in table III. It is plausible that due to feelings of shame, adolescents did not want to talk about sexual assaults and expressed them as "private events" instead.

One might posit that the twofold female-to-male ratio in PTSD which has been consistently reported in epidemiological studies in Mexico and internationally, ${ }^{1,2,30}$ as well as in our current study, is due to a greater exposure for females to traumas that are likely to develop into PTSD, that is, sexual trauma. However, some studies have addressed this point and found that the twofold risk of PTSD remains even after the sex distribution for type of trauma is held constant and thus cannot be explained by greater exposure to sexual assault. ${ }^{30-32}$ Rather, Breslau and her colleagues have found that women have a greater risk of developing PTSD than males after experiencing assaultive violence only and hypothesize that assaultive violence may affect women more because aggressors are more likely to be male and thus more physically threatening and potentially injurious to females. ${ }^{31}$

The cumulative number of events is also related to the probability of developing PTSD such that a history of several traumas weighs more than a single trauma in the development of PTSD. ${ }^{33}$ Those having experienced two or three LEs have more than three times the probability and those having experienced four or more LEs more than six times the probability of PTSD.

Considering this sample was composed only of non-institutionalized adolescents and permanent MCMA residents, it is very likely that the prevalence of LEs -as well as of PTSD- is underestimated, since those who have no permanent residence or live in government institutions (such as correctional institutions or orphanages) may have higher early and/or actual ${ }^{34}$ rates of exposure to violent life events. Another source of under-estimation may be due to participants' unwillingness to disclose information, particularly for emotionally charged or embarrassing events. The inclusion of a "private event", for which the participants could discuss related symptoms without revealing the content of the event, was implemented to reduce this type of response bias. Since people with PTSD could recall their LE in a different way than people without PTSD, there is a chance of recall bias in this study. However, the structured nature of the CIDI interview, as well as the short time lived by adolescents, could limit this type of bias.

Due to the frequency of traumatic life events in adolescence, their potential to develop into PTSD and the disabling nature of PTSD trauma should be considered a main public health concern. Despite that PTSD is one of the most disabling of the anxiety disorders, ${ }^{35}$ its impact upon primary care for the adolescent population has been insufficiently studied. Research suggests that those who experience trauma and suffer from PTSD are not being adequately detected by health services. ${ }^{36,37}$ Increased research in this area is needed in order to improve detection and timely mental health attention.

\section{Acknowledgments}

The Mexican Adolescent Mental Health Survey was supported by the National Council on Science and Technology (CONACyT CB-2006-CO1-60678) in conjunction with the Ministry of Education (grant No. CONACyTSEP-SSEDF-2003-CO1-22) and the National Institute of Psychiatry Ramon de la Fuente (DIES-4845). The survey was carried out in conjunction with the World Health Organization World Mental Health (WMH) Survey Initiative. We thank the WMH staff for assistance with instrumentation, fieldwork, and data analysis. These activities were supported by the United States National Institute of Mental Health (R01MH070884), the John D. and Catherine T. MacArthur Foundation, the Pfizer Foundation, the US Public Health Service (R13MH066849, R01-MH069864, and R01 DA016558), the Fogarty International Center (FIRCA R01-TW006481), the Pan American Health Organization, Eli Lilly and Company, Ortho-McNeil Pharmaceutical, Inc., GlaxoSmithKline, and Bristol-Myers Squibb. A complete list of WMH publications can be found at http://www.hcp. med.harvard.edu/wmh/. We also wish to thank Sandra Morales and Alejandro Hernandez for their assistance with pilot work and field supervision. Partial funding for this work also came from the American Foundation for Suicide Prevention (Guilherme Borges, PI).

\section{References}

I. Medina-Mora ME, Borges G, Lara C, Ramos-Lira L, Zambrano J, Fleiz C. Prevalencia de sucesos violentos y de trastorno por estrés postraumático en la población mexicana. Salud Publica Mex 2005;47:8-22.

2. Kessler RC. Posttraumatic stress disorder: the burden to the individual and to society. J Clin Psychiatry 2000;6I (suppl 5):4-I2.

3. Lucio E, León I, Durán C, Bravo E, Velasco E. Los sucesos de vida en dos grupos de adolescentes de diferente nivel socioeconómico. Salud Mental 200I;24:17-24.

4. La salud del adolescente en cifras. Salud Publica Mex 2003;45:SI53-

SI66.

5. Santos-Preciado JI,Villa-Barragán JP, García-Avilés MA, León-Álvarez G, Quezada-Bolaños S, Tapia-Conyer RT. La transición epidemiológica de las y los adolescentes en México. Salud Publica Mex 2003;45:SI40-SI 52.

6. Medina-Mora ME,Aguilar-Gaxiola S. Implementation of international research projects. Conference on strengthening mental health research capacity in Latin America and the Caribbean; 2006 Dec 6; Mexico City, México.

7. El-Shikh H, Fahmy E, Michael VS, Moselhy HF.Acontecimientos vitales y adicción: una revisión de la bibliografía. Eur J Psychiat 2004;|18:162-170. 
8. Ramos-Lira L, Saldívar-Hernández G, Medina-Mora ME, Rojas-Guiot E, Villatoro-Velázquez J. Prevalencia de abuso sexual en estudiantes y su relación con el consumo de drogas. Salud Publica Mex 1998;40:22I-233. 9. Pardo G, Sandoval A, Umbarila D.Adolescencia y depresión. Rev Colomb Psicol 2004;13-28.

10. Molnar BE, Berkman LF, Buka SL. Psychopathology, childhood sexual abuse and other childhood adversities: relative links to subsequent suicidal behaviour in the US. Psychol Med 2001;31:965-977.

I I. Molnar BE, Buka SL, Kessler RC. Child sexual abuse and subsequent psychopathology: results from the National Comorbidity Survey. Am J Public Health 2001;91:753-760.

12.Valdez-Santiago R, Hijar-Medina M. II. Del silencio privado a las salas de urgencias: la violencia familiar como un problema de salud pública. Gac Med Mex 2002;138:159-163.

13. Kilpatrick DG, Ruggiero KJ,Acierno R, Saunders BE, Resnick HS, Best CL.Violence and risk of PTSD, major depression, substance abuse/dependence, and comorbidity: results from the National Survey of Adolescents.J Consult Clin Psychol 2003;71:692-700.

14. Ramos-Lira L, Saltijeral MT, Caballero MA. Impacto de la violencia en la salud mental. Estado actual y perspectivas. Salud Ment 1996; 19:19-32.

15. Sauceda-García JM. III. La salud mental y la violencia familiar dirigida al menor. Gac Med Mex 2002; 138:164-168.

16. Ballenger JC. Focus on posttraumatic stress disorder. 4th meeting of the International Consensus Group on Depression and Anxiety. Montecatini, Italy, April 1999.J Clin Psychiatry 2000;6I (suppl 5):3-66. 17. Palacios L, Heinze G. Trastorno por estrés posttraumático: una revisión del tema (primera parte). Salud Ment 2002;25:19-26.

18. Medina-Mora ME, Borges G, Lara C, Benjet C, Blanco J, Fleiz C, et al. Prevalencia de trastornos mentales y uso de servicios: Resultados de la Encuesta Nacional de Epidemiología Psiquiátrica en México. Salud Ment 2003;26: I- 16.

19. Baker CK, Norris FH, Díaz DM, Perilla JL, Murphy AD, Hill EG.Violence and PTSD in Mexico: gender and regional differences. Soc Psychiatry Psychiatr Epidemiol 2005;40:519-528.

20.The World Health Organization (WHO) World Mental Health (WMH) Survey Initiative version of the Composite International Diagnostic Interview (CIDI). World Mental Health. [Accessed: Jan, 2007]. Available at: http://www.hcp.med.harvard.edu/wmhcidi/.

21.American Psychiatric Association. DSM-IV: Diagnostic and statistical manual of mental disorders. 4th ed.Washington, DC:American Psychiatric Association, 1994.

22. Benjet C, Medina-Mora ME, Borges G, Cruz C, Blanco J, Fleiz C, et al. Mexican Adolescent Mental Health Survey:An overview of Design and Field Procedures. México, DF: Instituto Nacional de Psiquiatría, 2007. 23. Benjet C, Borges G, Medina-Mora ME, Fleiz C, Blanco J, Zambrano J et $\mathrm{al}$. Prevalence and socio-demographic correlates of drug use among adolescents: results from the Mexican Adolescent Mental Health Survey. Addiction 2007; 102:126|-|268.
24. Benjet C, Borges G, Medina-Mora ME, Blanco J, Zambrano J, Orozco $R$, et al. Drug use opportunities and the transition to drug use among adolescents from the Mexico City Metropolitan Area. Drug Alcohol Depend 2007;90:128-134.

25. Kessler RC, Sonnega A, Bromet E, Hughes M, Nelson CB, Breslau N. Epidemiological Risk Factors for Trauma and PTSD. En:Yehuda R, comp. Risk Factors for Posttraumatic Stress Disorder. Ia. ed.Washington, DC: American Psychiatric Press, 1999:23-60.

26. Breslau N, Kessler RC, Peterson EL. Post-traumatic stress disorder assessment with a structured interview: reliability and concordance with a standardized clinical interview. Int J Methods Psychiatr Res 1998;7:I21-I27. 27. Research Triangle Institute. SUDAAN Language Manual, Release 9.0. Research Triangle Park, NC: Research Triangle Institute, 2004.

28. INEGI. Coordinaciones Estatales del INEGI. INEGI; [Accessed: Jan, 2007]. Available at: http://www.observatoriolaboral.gob.mx/conteol.asp. 29. Goldberg LR, Freyd J]. Self-reports of potentially traumatic experiences in an adult community sample: gender differences and testretest stabilities of the items in a brief betrayal-trauma survey. J Trauma Dissociation 2006;7:39-63.

30. Zlotnick C, Johnson J, Kohn R,Vicente B, Rioseco P, Saldivia S. Epidemiology of trauma, post-traumatic stress disorder (PTSD) and comorbid disorders in Chile. Psychol Med 2006;36:1523-I533.

31. Breslau N, Chilcoat HD, Kessler RC, Peterson EL, Lucia VC.Vulnerability to assaultive violence: further specification of the sex difference in posttraumatic stress disorder. Psychol Med 1999;29:8I3-82I.

32. Kessler RC, Sonnega A, Bromet E, Hughes M, Nelson CB.

Posttraumatic stress disorder in the National Comorbidity Survey. Arch Gen Psychiatry 1995;52: 1048-1060.

33. Brock SE. Identifying individuals at risk for psychological trauma. National Association of School Psychologists; [Accessed: Jan, 2007].Available at: http://www.nasponline.org/resources/crisis_safety/l9-Brock.pdf. 34. Lo básico sobre la violación entre rejas. Santa Barbara Rape Crisis Center. [Accessed Jan, 2007]. Available at: http://www.sbrapecrisiscenter. org/05Volunteer/Marzo\%202005.pdf.

35. Benjet C, Medina-Mora ME, Borges G, Cruz C, Lara C, Blanco J, et al. 12 month prevalence, service use and demographic correlates of DSM-IV psychiatric disorders in Mexican adolescents: Results from the Mexican Adolescent Mental Health Survey. Conference on strengthening mental health research capacity in Latin America and the Caribbean; 2006 Dec 7; México City, Mexico.

36. Ballenger JC, Davidson JR, Lecrubier Y, Nutt DJ, Marshall RD, Nemeroff $\mathrm{CB}$, et al. Consensus statement update on posttraumatic stress disorder from the international consensus group on depression and anxiety.J Clin Psychiatry 2004;65(suppl I):55-62.

37. Lecrubier Y. Posttraumatic stress disorder in primary care: a hidden diagnosis. J Clin Psychiatry 2004;65(suppl I):49-54. 


\title{
Appendix \\ Traumatic events questions of the World Mental Health adolescent version of the Composite International Diagnostic InTERview (WMH-CIDI-A)*
}

\author{
Sexual abuse \\ Raped \\ when you were so small that you didn't know what was happening. Did this ever happen to you? \\ Sexually assaulted \\ Domestic violence \\ Beaten up by caregiver \\ 3 Were you ever badly beaten up by your parents or the people raising you? \\ Witnessed physical fights at home \\ 4 Did you ever witness serious physical fights at home, like your father beating up your mother?
}

I The next two questions are about sexual assault. The first is about rape. We define this as someone either having sexual intercourse with you or penetrating your body with a finger or object when you did not want them to, either by threatening you, by using force or

2 Other than rape, were you ever sexually assaulted, where someone touched you inappropriately, or when you did not want them to?

Disaster natural or man-made

In region of terror

5 Were you ever in a place where there was a war, revolution, military coup, or where there was ongoing terror of civilians for political, ethnic, religious or other reasons?

Disaster

6 Were you ever involved in a major natural disaster, like a devastating flood, hurricane, or earthquake?

Accident or illness

Toxic exposure/ Automobile/ Life threatening accident

7 Were you ever exposed to a poisonous chemical or substance that could cause you serious harm?

8 Were you ever involved in a serious or life-threatening car accident?

9 Were you in any other serious or life- threatening accident?

Life threatening illness

10 Did you ever have a life-threatening illness?

Violence

Beaten up by romantic partner or someone else

II Were you ever badly beaten up by someone you were dating or with whom you were romantically involved?

12 Were you ever badly beaten up by anyone else?

Mugged or threatened with a weapon

13 Were you ever mugged, held up, or threatened with a weapon? Stalked

14 Has someone ever stalked you - that is, followed you or kept track of your activities in a way that made you feel you were in serious Kidnapped danger?

15 Were you ever kidnapped or held captive?

Death or trauma of a loved one

Unexpected death of a loved one

16 Did someone very close to you ever die unexpectedly; for example, they were killed in an accident, murdered, committed suicide, or had a fatal heart attack at a young age?

Traumatic event of a loved one

17 Did anyone very close to you ever have a very stressful or life-threatening experience, like being kidnapped, tortured or raped?

Death or trauma of someone else

Witnessed death or dead body or saw someone else seriously hurt

18 Did you ever see someone being badly injured or killed, or unexpectedly see a dead body?

Accidentally caused serious injury or death

19 Did you ever do something that accidentally led to the serious injury or death of another person?

Purposely injured, tortured or killed someone

20 Did you ever on purpose either seriously injure, torture, or kill another person?

Other/ Private event

2I Were you ever a refugee - that is, did you ever flee from your home to a foreign country or place to escape danger or persecution?

22 Did you ever experience any other extremely upsetting or life-threatening event that I haven't asked about yet?

23 Sometimes people have experiences they don't want to talk about in interviews. I won't ask you to describe anything like this, but, without telling me what it was, did you ever have an extremely upsetting or life-threatening event that you didn't tell me about because you didn't want to talk about it?

*Traumatic events are not shown in the order presented to participants 